It is submitted that the following extended definition can be applied to all cases:

It is assumed that all the component parts of the steam plant are perfect, and that there are no losses due to initial condensation, leakage, radiation, or conduction, and that there is no clearance in the cylinder. The feed-water required is taken into the boiler at the exhaust temperature, and its temperature is gradually raised until that corresponding to saturated steam is reached. Steam is then formed at constant pressure until dry saturated steam is produced, after which, if the steam is to be superheated, heat is added at constant pressure and at increasing temperature, until the required temperature of superheat is reached. The steam is introduced into the cylinder at constant pressure, displacing the piston, and performing external work equal to the absolute pressure multiplied by the volume swept through by the piston up to the point of cut-off. Beyond that point expansion takes place adiabatically, doing work until any desired pressure is reached, when the steam is reheated at constant pressure to any desired temperature whence adiabatic expansion takes place; such reheating process can be repeated as often as desired. Finally, the steam is expanded adiabatically until the temperature of saturation corresponding to the boiler pressure is met. From this point, either adiabatic expansion continues doing work until the pressure in the cylinder is equal to the back pressure against which the engine is working, or the steam is expanded so that a portion of the heat is transferred to the feed-water in such a manner that at every temperature the amount of heat so transferred is equal to the increase in water-heat at that temperature, until the pressure in the cylinder is equal to the back pressure against which the engine is working. The steam is then completely exhausted from the cylinder at constant pressure corresponding with the lower limit of temperature, work being done on the steam by the engine during exhaust, equal to the absolute back pressure multiplied by the total volume swept through by the piston. The steam is thus removed from the cylinder and the cycle is complete.

In practice, the following main cases occur resulting from the omission of one or more of the factors of the comprehensive definition :

(I) Saturated steam with simple adiabatic expansion to the back pressure.

(2) Superheated steam with simple adiabatic expansion to the back pressure.

(3) Superheated steam with one or more reheats with final adiabatic expansion to the back pressure.

(4) Saturated or superheated steam with feedheating expansion to the back pressure.

(5) Superheated steam with one or more reheats, and final feed-heating expansion to the back pressure.

The thermal efficiency of any heat engine is defined as the ratio of the heat utilised as work to the heat supplied. Capt. Sankey gives some worked-cut examples to illustrate the method, and makes use of the Mollier chart and of Callendar's Fahrenheit Steam Tables. He also includes tables of results of a large number of other calculations for different cases, and includes among these one illustrating the Benson cycle, in which steam is generated at the critical temperature $\left(706^{\circ} \mathrm{F}\right.$.) at a pressure of $3200 \mathrm{lb}$. per sq. inch absolute. For comparison, the thermal efficiencies of a gas engine and of an oil engine have also been worked out and are included in the tables.

Capt. Sankey's memorandum gives some idea of the arduous task which the Committee has had to face, and the final recommendations will be welcomed by the engineering profession.

\title{
Parker Plant for Low Temperature Carbonisation.
}

TTENTION has already been directed in NATURE A (September 20, p. 44I) to the Government offer to test at public expense approved processes for the carbonisation of coal at low temperatures. The Low Temperature Carbonisation Company, Ltd., has been quick to submit for test the standard unit of "Parker" plant installed near Barnsley at Barugh (locally pronounced " bark," it may be added for the enlightenment of the uninitiated). The Department of Scientific and Industrial Research has now issued a report of the test made in July last. The Director of Fuel Research in a prefatory note emphasises that the report is on technical results only, and that " no attempt is made to pronounce on the commercial possibilities of the plant."

The coal is carbonised in vertical iron tubular retorts, $9 \mathrm{ft}$. long and of average diameter of $5 \mathrm{in}$., the retorts being cast in groups of 12 assembled in a setting of 32 groups. The setting is heated by the gas made, and is equipped with closed chambers below the retorts to receive the coke after carbonisation, and allow it to cool without quenching and consequent contamination with moisture. Such a setting was designed to have a throughput of 50 tons of coal per day, and in the test, lasting two days, it was found that this claim was substantiated.

The coal employed was " Dalton Main," with which the Fuel Research Station had already considerable experience. It was a washed slack, fairly dry, containing 5 per cent. only of ash-a low figure for commercial supplies of coal. The yields of products per ton of coal as charged were :

Coke . . . $13.92 \mathrm{cwt}$.

Gas . . . 5620 cub. ft. or 39.6 therms.

NO. $2 \$ 77$, vOL. I I 4$]$

\section{Tar . . . I8.62 gallons.}

Crude Spirit (motor) . I·78 gall. yielding I $\cdot 39$ gall. of refined product.

Liquor . . . . 26 gall., equivalent to $13.55 \mathrm{lb}$. of ammonium sulphate.

The coke produced, the report states, was of suitable size, not friable, contained little breeze, and only 4 per cent. of volatile matter. It successfully withstood an eight-day railway journey to the Fuel Research Station, was readily ignited in a household grate, and gave a good hot fire. It would appear, therefore, that the claim that the process produced a smokeless domestic fuel was substantiated. The analysis showing a volatile content of some 4 per cent. raises a doubt as to whether this fuel will develop the " cheerful blaze" which is so attractive to lovers of a coal fire, and contributes so much to speed of ignition.

The yield of tar was high, and chemically it was of the "low temperature " character. The yield of crude motor spirit was moderate, but the refining loss and consequent cost was considerable. The quantity of ammonia recovered per ton was good for low temperature practice, though low judged by existing carbonising practice, while the liquor obtained was so dilute that it is considered doubtful whether recovery was commercially justifiable.

The whole of the rich gas made was employed in heating the setting, supplemented by some producer gas specially generated. Compared with modern carbonising practice, this is a high fuel consumption, and it is pointed out in the report that a reduction could be effected by better design of the plant. The loss of this rich gas is more serious commercially, as the gas is the most valuable and least speculative 
by-product of low temperature carbonisation. It may be assumed that the gas will eventually be put to some better use than heating the setting, for otherwise the financial burden of the process would have to be carried entirely by the coke and the tar and light oilconditions which do not hold promise of smokeless fuel at a low price. As regards the economics of the process in general, though the report expresses no opinion, the data given as to plant and labour do not suggest low costs when compared with those of current carbonising practice.

The general impression which the report conveys is that the process yields a carbonised fuel rega ded as meeting domestic requirements which will probably prove costly per ton, and the scope of the process will depend on whether the general public will be prepared to pay the price for such smokeless fuel in order to avoid the atmospheric pollution following the use of raw coal.

H. J. H.

\section{Applied Science at the University of Brussels.}

THE highly successful celebrations in connexion with the fiftieth anniversary of the founding of the Applied Science School of the University of Brussels were held in the latter half of November, and were attended by the King of the Belgians, who received the foreign delegates, and also by the Duke of Brabant, who laid the foundation stone of a new building which will continue the development of the University. The city of Brussels and private donors have contributed largely to this scheme, as also the American Committee for the relief of Belgium. Great progress has been made in the buildings for pure and applied science at Solbosch, on the outskirts of Brussels, where, with ample space at disposal, it has been possible to erect a very fine block of buildings in the form of a hollow square.

Physics and chemistry are very well housed and equipped, and especial care has been taken to provide a number of small rooms for research work. The electrical engineering laboratories are remarkably well planned, and especially so as regards the arrangement of their numerous power circuits, which are carried round the walls below the windows and are protected by wire grillages. These circuits are connected to a number of panel units also completely enclosed and provided with the usual resistances, switch gear and measuring instruments all connected up in such a manner that students can readily trace out the various circuits, to which access is gained by numerous doors.

The main laboratory for investigating the strength and other physical properties of materials is chiefly notable for a fine equipment of Amsler testing machines housed in a spacious room provided with an overhead crane, and there are also a considerable number of accessory instruments for measurement and calibration work. A special photo-elastic laboratory is also arranged for in connexion with this department.

The laboratories for technical thermodynamics and hydraulics are now in course of equipment and are on a large scale typical of continental views of such matters, and, like the other laboratories, have welllighted basements with considerable head room, an arrangement which is especially convenient for steam plants and machinery dealing with the flow of liquids.

In connexion with the celebrations, a number of scientific and technical addresses were given, and numerous other functions were arranged by the Government, the University, and the civic authorities. E. G. C.

\section{University and Educational Intelligence.}

ABERDEEN.-The University Court has appointed Dr. A. Bowman to the lectureship on the scientific study of fisheries, in succession to Dr. T. Wemyss Fulton, resigned.

Prof. A. Findlay has proceeded on leave of absence to the United States, where he will act as substitute professor of chemistry at Leland Stanford University for the next nine months.

CAMBRIDGE.--The report of the Botanic Garden Syndicate refers to continued financial anxiety despite the generous support of Mr. Reginald Cory. A prospective legacy from an old friend of the Garden is referred to in the report at her special request in order that it may stimulate others to follow her excellent example. In the recent death of Mr. R. I. Lynch, Curator of the Garden from I879 until I9I9, a link with the past has been snapped. One item of interest in the report is the exchange of shrubs from the Garden for birds from the Zoological Society of London, two pairs of mandarin ducks having been recently received.

The John Bernard Seely Prize, formerly given for an essay in aeronautics, is in future to be awarded to the candidate who does best in aeronautics in the Mechanical Sciences Tripos.

Edinburgh.-Sir Richard Lodge, who has been Dean of the Faculty of Arts for thirteen years, has resigned this office, and the Faculty has elected Prof. E. T. Whittaker to succeed him as Dean. Prof. Hudson Beare and Prof. Lorrain Smith have been re-elected Deans of the Faculties of Science and Medicine respectively.

At its last meeting the University Court, on the recommendation of the Senatus, appointed Dr. Claude B. Ker, lecturer in infective fevers, to be a senior lecturer, with a seat on the Faculty of Medicine and on the Senatus, and Dr. E. M. Horsburgh, reader in technical mathematics, to be a member of the Senatus.

Dr. Douglas A. Allan, at present an assistant in the Department of Geology, has been appointed lecturer in geology in Armstrong College, University of Durham.

LoNDON.-The following doctorates have been awarded :-Ph.D. (Science), Mr. R. E. W. Maddison (King's College) for a thesis entitled "Part I. : The action of light on chlorine water and aqueous hypochlorous acid solutions; Part II.: Retardation and acceleration of certain chemical reactions by light of different wave-lengths "; Sachindranath Sen (Imperial College-Royal College of Science) for a thesis entitled "On the design of the Kew pattern barometer.'

We learn from the Chemiker Zeitung that Prof. A von Parseval has been nominated to the newly instituted chair of aviation at the Munich Technical Hochschule; and that Dr. Wilhelm Eitel, professor of physico-chemical mineralogy and petrography at Königsberg, has been invited to the chair of mineralogy
at Freiburg-im-Breisgau.

Applications are invited from medical graduates for the Marks lectureship in applied physiology and the Sheridan fellowship in the University of Adelaide. The applications, with testimonials, statement of academic qualifications, published researches, and a recent photograph, should be sent before the end of January, marked outside "Application for Marks Lectureship," to the Vice-Chancellor of the University, c/o the Agent-General for South Australia, Australia
House, Strand, W.C.2. 